\title{
SABER CIENTÍFICO E CONHECIMENTO ESPONTÂNEO: OPINIÕES DE ALUNOS DO ENSINO MÉDIO SOBRE TRANSGÊNICOS
}

\author{
Scientific and spontaneous knowledge: \\ High School students' opinions on transgenics
}

\author{
Vanessa Daiana Pedrancini ${ }^{1}$ \\ Maria Júlia Corazza-Nunes ${ }^{2}$ \\ Maria Terezinha Bellanda Galuch ${ }^{3}$ \\ Ana Lúcia Olivo Rosas Moreira ${ }^{4}$ \\ William Mário de Carvalho Nunes ${ }^{5}$
}

Resumo: Objetivou-se investigar o que alunos da etapa final da educação básica sabem sobre transgênicos e quais suas opiniões sobre as aplicações e implicações desta biotecnologia. A investigação foi realizada por meio de questionários aplicados a cem alunos do $3^{\circ}$ ano do Ensino Médio de três escolas estaduais da região Noroeste do Paraná. Para analisar quanti e qualitativamente os dados, foram agrupadas as respostas que expressam o entendimento dos alunos sobre a questão. A análise indicou que todos os alunos já haviam ouvido falar sobre transgênicos, seja por meio de notícias divulgadas pela mídia ou situações de ensino. Observou-se que a mídia exerceu grande influência no modo como os alunos responderam às questões, em especial em suas opiniões sobre as vantagens e desvantagens dos transgênicos. Este estudo revela que o modo como o ensino é organizado e desenvolvido muitas vezes pouco contribui para que o aluno desenvolva uma compreensão que se difere daquela adquirida em situações não escolares.

Palavras-chave: Biotecnologia. Transgênicos. Educação.

\begin{abstract}
This research investigates the knowledge that High School students have on transgenics and their opinions on the application and implications of this type of biotechnology. Questionnaires were given to one hundred final year High School students in three government schools in the northwestern region of the state of Paraná, Brazil. Answers were grouped according to the students' knowledge of the subject so that quantitative and qualitative data analysis could be carried out. Data analysis showed that all students had already been informed on transgenics, by news from the social media or learned in the classroom. The social media highly affects the way students reported the questions, particularly with regard to the advantages and disadvantages of transgenics. Current research reveals that the teaching and development of biological studies contribute only slightly towards a different concept from that acquired in extra school situations.
\end{abstract}

Key words: Biotechnology. Transgenics. Education.

\footnotetext{
${ }^{1}$ Mestranda em Educação para a Ciência e o Ensino de Matemática, Universidade Estadual de Maringá (UEM). Maringá, PR. <vapedrancini@yahoo.com.br>; <pedrancini@hotmail.com>

${ }^{2}$ Doutora em Ciências Biológicas; docente, Departamento de Biologia/DBI, UEM. Maringá, PR.

<mjcnunes@uem.br>;<mjcorazzanunes@gmail.com>

${ }^{3}$ Doutora em Educação: História, Política, Sociedade; docente, Departamento de Teoria e Prática da Educação, UEM. Maringá, PR. <galuch@brturbo.com.br>; <mtbgaluch@uem.br>

${ }^{4}$ Doutora em Ecologia e Recursos Naturais; docente, DBI, UEM. Maringá, PR. <alormoreira@uem.br>

${ }^{5}$ Doutor em Agronomia; docente, Departamento de Agronomia, UEM. Maringá, PR. <wmcnunes@uem.br>

${ }^{1}$ Rua Zacarias Vasconcelos, 350

Centro - Mandaguari, PR

86.975-000 


\section{Introdução}

Estudos realizados por pesquisadores nacionais e internacionais sobre o processo de ensino e aprendizagem de ciências têm revelado que os alunos apresentam concepções, ou seja, conceitos intuitivos, espontâneos, alternativos que, muitas vezes, distanciam-se dos conhecimentos científicos e podem se comportar como obstáculos à aprendizagem desses conhecimentos (BIZZO e KAWASAKI, 1999; BASTOS, 1998; CABALLER e GIMÉNEZ, 1993). Estas idéias ou crenças, geralmente de bases empíricas, são saberes que o sujeito adquire, não raro nas vivências diárias, em ambientes não escolares. Segundo Natadze (1991), as propriedades visuais dos objetos são facilmente identificadas e abstraídas pela criança. Porém, a assimilação dos elementos essenciais do conceito só ocorre posteriormente.

De acordo com Bizzo e Kawasaki (1999) e Bachelard (1996), as idéias alternativas dos alunos podem ser o ponto de partida para o aprendizado do saber científico nas atividades didáticas planejadas e desenvolvidas de modo intencional. Como ressaltam Bastos (1998) e Bachelard (1996), a apropriação do conhecimento científico não ocorre pela continuidade dos saberes de senso comum, ou seja, a aprendizagem de novos conteúdos requer mudanças conceituais similares àquelas ocorridas nas revoluções científicas. Observa-se, nessas revoluções, que o conhecimento científico tem avançado por meio de rupturas e descontinuidades e não pelo simples acúmulo de informações. No entanto, segundo Bizzo e Kawasaki (1999), mediar essa ruptura é uma tarefa difícil se o professor não dominar os conteúdos que ministra, de modo a reconhecer as diferenças entre esses dois âmbitos do conhecimento, pois "caso o aluno [...] seja estimulado a elaborar modelos explicativos apenas tomando seus pontos de vista pessoais como referência, a escola passa a ser o local onde as crenças e conhecimentos prévios do estudante simplesmente afloram e se cristalizam" (p. 27).

Pesquisas nacionais e internacionais (PEDRANCINI et al., 2007; GIORDAN e VECCHI, 1996; BANET e AYUSO, 1995; BUGALLO, 1995) têm revelado que muitos alunos inclusive que já concluíram ou estão terminando a educação básica - continuam apresentando explicações que se limitam às propriedades sensoriais de vários fenômenos, mesmo depois de os terem estudado em diferentes níveis de escolaridade e de a aprendizagem em relação a esses fenômenos ter sido considerada satisfatória nas avaliações.

Desse modo, observa-se que, apesar de estarmos vivendo uma era de ricas descobertas científicas e tecnológicas, discutidas no contexto escolar e constantemente divulgadas por meios acadêmicos e multimidiáticos, de modo a fazerem parte do cotidiano das pessoas, a maioria da população sente-se despreparada para emitir opiniões fundamentadas sobre temas, tais como transgenia, clonagem e genômica. Isto demonstra que nem sempre os conhecimentos adquiridos na escola possibilitam que os sujeitos ultrapassem o saber de senso comum ou as primeiras impressões adquiridas na vivência.

Segundo Giordan e Vecchi (1996), cresce cada vez mais a defasagem entre uma minoria que se apropriou do saber sistematizado e a maioria dos sujeitos que continua analisando os fatos com base em saberes espontâneos, trazendo conseqüências culturais e sociais no mundo em que a maioria dos problemas de gestão tem base científica. Ressaltando-se o papel da escola nesse cenário, os autores consideram que esta instituição não pode mais se limitar à transmissão de um programa de conhecimentos enciclopédicos, temporariamente retidos pelos alunos, mas deve, em primeiro lugar, trabalhar com conhecimentos de modo 
Saber científico e conhecimento espontâneo...

que estes possam ser generalizados para a resolução de problemas e entendimento de situações que fazem parte da realidade atual.

Nesse contexto, não podemos deixar de mencionar estudos que têm demonstrado que os próprios docentes sentem dificuldades para compreender temas relacionados aos conhecimentos produzidos na atualidade e, conseqüentemente, organizar um ensino que promova, no aluno, a capacidade de posicionar-se de forma esclarecida acerca de tais conhecimentos (AMORIM, 1997).

Cresce o número de pesquisadores em educação que se dedicam a investigar como ocorrem os processos de aquisição de conhecimentos pelos estudantes. Essas informações são de grande valia para provocar reflexões sobre a prática pedagógica vigente na maioria das escolas e orientar futuras ações docentes e discentes. Todavia, é imprescindível refletir sobre o modo pelo qual a criança em processo de aprendizagem escolar se apropria dos conceitos científicos. Sobre esta questão, Vygotsky (2001, p. 246) diz que "um conceito é mais do que a soma de certos vínculos associativos formados pela memória; é mais do que um simples hábito mental; é um ato real e complexo de pensamento que não pode ser aprendido por meio de simples memorização [...]".

Considerando-se esta assertiva, o presente estudo teve como objetivo investigar o que os alunos do Ensino Médio sabem sobre transgênicos e quais suas opiniões sobre as aplicações e implicações desta biotecnologia, tendo em vista a educação escolar.

\section{Procedimentos metodológicos}

Para a obtenção dos dados foram elaboradas questões dissertativas, abrangendo conceitos básicos e questões polêmicas sobre transgênicos. Anteriormente à aplicação do questionário aos alunos, foi realizado um teste piloto com três estudantes do Ensino Médio. Uma vez realizado o teste piloto e procedidas as alterações necessárias no instrumento para a coleta de dados, o questionário foi aplicado a cem alunos do $3^{\circ}$ ano do Ensino Médio, de três escolas estaduais da região Noroeste do Paraná, com idade entre 16 e 23 anos. Os alunos responderam às seguintes questões:

1. Você já ouviu falar sobre os transgênicos?

2. O quê você entende sobre transgênico?

3. Você acha que existe alguma diferença entre Organismos Geneticamente Modificado (GMs) e os transgênicos?

4. Como você acha que se faz um transgênico?

5. Você conhece algum transgênico? Cite exemplos.

6. Na sua vida cotidiana você tem utilizado algum transgênico?

7. Quais as vantagens que você vê em fazer os transgênicos?

8. Na sua opinião, quais são as desvantagens desta técnica?

9. Você é contra ou a favor dos transgênicos? Por quê? 


\section{Análise dos dados}

Todos os alunos que participaram da pesquisa disseram já ter ouvido falar sobre transgênicos. Alguns complementaram suas respostas descrevendo que obtiveram tais informações por meio de jornais, revistas, televisão ou que os haviam estudado na escola. Todavia, é interessante ressaltar que as manifestações dos alunos em relação ao que sabiam sobre o assunto revelam que a contribuição da escola na aquisição desse conhecimento pouco se difere da que acontece por meio de jornais, revistas, rádio e televisão: "Já, pouco, pois na escola não é muito comentado"; "Sim, bastante, principalmente na TV e nas revistas"; "Sim, até mesmo fizemos um trabalho na escola sobre os mesmos".

Em seus posicionamentos sobre o que entendiam por transgênicos, a maioria dos estudantes utilizou, ainda que superficialmente, conceitos genericamente divulgados pela mídia, sendo bastante comum nas respostas a expressão "... geneticamente modificado(a)". Em relação ao que pode ser geneticamente modificado, as respostas vacilaram entre "organismo", "planta", "alimento", "matéria", "semente" ou, ainda, "gene". Sete estudantes revelaram que transgênico é simplesmente um "produto", "planta" ou "alimento modificado", sem especificar, no entanto, que tipo de modificação sofreram: "A célula reprodutora é modificada, deixando de produzir novos frutos".

Esta idéia alternativa resulta, provavelmente, de discussões divulgadas pela mídia sobre a regulamentação da tecnologia Termination, que promove a esterilização genética de sementes, sob o argumento de prevenir o fluxo indesejado de genes de cultivo geneticamente modificados. Sobre esta questão, estudiosos e agentes de biossegurança (contrários a esta biotecnologia) ligados a órgãos governamentais e a ONGs refletem que, ao promover o gene Termination como uma solução de biossegurança, a indústria biotecnológica procura dissimular seu verdadeiro objetivo: proteger as patentes das corporações e maximizar os lucros, forçando os agricultores a comprar novas sementes a cada safra (ANDRIOLI, 2006).

Outros alunos ampliaram suas respostas, considerando que a modificação é artificial ou realizada no laboratório: "São organismos geneticamente modificados, são criados em laboratório".

Ao responder à quarta questão, a maioria dos alunos que emitiu esses conceitos escreveu simplesmente que os transgênicos são "feitos", "modificados" ou "modificados geneticamente" no laboratório ou, ainda, por meio da engenharia genética. Alguns conceberam que um transgênico pode ser feito "modificando seu gene" ou "fazendo alteração do DNA do alimento", enquanto outros revelaram não saber.

Estas respostas trazem elementos reveladores de que os alunos não compreenderam o significado de "geneticamente modificado". Suas idéias reproduzem informações confusas, fragmentadas, que não se aproximam do conceito. Pairam, isto sim, sobre informações veiculadas pelos meios de comunicação de massa ou até por discussões realizadas na escola, com o objetivo de levar os alunos a emitir opiniões sobre um assunto polêmico sem que tenham conhecimentos com os quais possam pensar sobre os fenômenos. Por isso, prevalecem idéias alternativas como: "Pode-se fazer um transgênico pela mistura de uma planta mais resistente com outra. Tipo enxertia".

Entre os alunos que utilizaram o conceito "geneticamente modificado", oito manifestaram possuir algum entendimento dessa expressão ao explicar como se faz um transgêni- 
co. Eis o que disseram: "Por exemplo, você pega uma planta, coloca o gene de uma praga e ela será mais resistente"; "No laboratório é implantado um gene de outro indivíduo no seu DNA".

Alguns alunos consideraram que transgênico é "uma planta na qual seu gene foi geneticamente modificado", "organismos que têm seus genes modificados artificialmente", ou, ainda, "que sofreram uma mutação genética em seus genes, alterando sua forma natural". Conseqüentemente, para se fazer um transgênico basta "alterar o gene do organismo", "modificar um gene do grão".

Por definição, o termo transgênico refere-se a qualquer organismo, microrganismo, animal ou planta que, por transformação, teve sua constituição genética alterada pela introdução de gene(s) de um outro organismo, em geral de uma outra espécie (KREUZER e MASSEY, 2001; TORRES, CALDAS e BUZO, 1999). Conseqüentemente, denomina-se transformação a alteração genética ocorrida em uma célula resultante da incorporação estável de material genético exógeno em seu genoma. Trata-se, portanto, de um evento integrativo (QUECINE e VIEIRA, 2001). Por outro lado, são considerados mutantes células ou organismos que manifestam uma nova característica ao tornarem-se portadores de novos alelos, resultantes de uma alteração na seqüência de bases de seu DNA (KREUZER e MASSEY, 2001; SUZUKI et al., 1989). Temos que considerar que na transgenia é possível que a inserção ao acaso de um gene exógeno no genoma de um organismo venha a anular a função de um gene residente nesse organismo ou, ainda, interferir na regulação gênica, aumentando ou diminuindo a expressão de determinado gene (FARAH, 1997).

Nesse contexto, uma concepção distorcida, influenciada pela mídia, refere-se ao conceito de OGM (Organismo Geneticamente Modificado) que, não raro, é considerado sinônimo de transgênico. De acordo com a literatura, todo transgênico é um OGM, mas nem todo OGM é um transgênico, pois seqüências de um organismo podem ser externamente alteradas e reintegradas, por transformação, nesse mesmo organismo.

Quando os alunos da pesquisa foram questionados em relação à existência ou não de diferença entre OGMs e transgênicos, a maioria respondeu que "não existe diferença"; 7\% admitiram que existe, porém, não souberam explicá-la; e 14\% não responderam ou revelaram não saber se há diferença ou não. Entre os alunos que admitiram diferença entre OGM e transgênico, apenas um descreveu: "eu acho que sim, porque nem todos os OGMs são transgênicos, embora todos transgênicos sejam OGMs". No entanto, não acrescentou nada que pudesse indicar a compreensão do conceito. Esse fato leva à seguinte reflexão: os conhecimentos escolares pouco estão se transformando em elementos mediadores do pensamento, ou seja, saberes com os quais os sujeitos possam refletir e analisar questões extra-escolares.

Ainda entre as concepções sobre o que é transgênico, três alunos descreveram, simplesmente, que são alimentos ou sementes resultantes de reações químicas: "É uma química que usam para melhorar o desenvolvimento das sementes para que se desenvolvam melhor"; "Sei apenas, que são alimentos produzidos a partir de reações químicas e não são muito benéficos à saúde".

Ao refletir sobre essas concepções, temos que considerar que, embora o isolamento, a clonagem e a transferência de genes de um organismo para outro envolvem diversas reações químicas, as idéias dos alunos não revelam a compreensão desses processos. Isto pode ser observado nas respostas à quarta questão, nas quais estes e outros alunos, utilizando expressões semelhantes, conceberam que para se fazer um transgênico "injeta-se uma química na semen- 
te"; "coloca-se alguma substância dentro ou misturada com as sementes"; "você pega uma semente, estuda-a e coloca algo dentro dela para fazêe-la mais forte que a bactéria"; "em seu DNA implanta-se no laboratório uma outra proteina"; ou, ainda, "no exemplo do frango, coloca-se hormônios para fazêello crescer mais rápido".

Constata-se, por meio dessas concepções, que muitas vezes as informações fornecidas por livros, revistas, jornais e outros meios de comunicação, aliadas ao modo pelo qual o ensino é conduzido, não são suficientes para a abstração e generalização. Ao mesmo tempo, não se pode perder de vista que muitas dessas concepções, expressas por palavras, podem representar estágios do processo de desenvolvimento conceitual. Como ensina Vygotsky (2001, p. 246):

Os conceitos psicologicamente concebidos evoluem como significados das palavras. A essência do seu desenvolvimento é, em primeiro lugar, a transição de uma estrutura de generalização a outra. Em qualquer idade, um conceito expresso por uma palavra representa uma generalização. Mas os significados das palavras evoluem. Quando uma palavra nova, ligada a um determinado significado, é apreendida pela criança, o seu desenvolvimento está apenas começando; no início ela é uma generalização do tipo mais elementar que, à medida que a criança se desenvolve, é substituída por generalizações de um tipo cada vez mais elevado, culminando o processo na formação dos verdadeiros conceitos.

Para um dos alunos, por exemplo, "transgênico não é um clone, e sim um cruzamento de dois genes diferentes". Conseqüentemente, pode-se fazer um transgênico "cruzando genes diferentes, que não venham a apresentar os mesmos produtos".

A re-elaboração do conceito foi observada em $10 \%$ das respostas dos alunos, que ao definirem e explicarem o que é um transgênico, aproximaram-se das definições presentes na literatura, porém com palavras de seu próprio vocabulário. Consideraram, por exemplo, que: "transgênico é um organismo que carrega um gene que não é o dele" ou que "são alimentos geneticamente modificados por genes recebidos de bactérias, vírus [...]". Coincidentemente, a maioria desses alunos explicou que para se fazer uma planta transgênica "um gene de um animal, vírus on bactéria é implantado, em laboratório, nos alimentos", "são introduz̨idos genes de outros vegetais na seqüencia do gene que se quer modificar".

De acordo com Vygotsky (1991), a re-elaboração conceitual, termo sinônimo de aprendizagem, é um complexo processo, que envolve o nível social e, também, o individual. Primeiramente, o indivíduo interpreta palavras, termos, conceitos, definições utilizadas em seu meio sócio-cultural. Em seguida, os significados dessas palavras, termos, são reconstruídos e começam a fazer parte dos processos psicológicos internos deste indivíduo, transformandose em instrumentos de seu pensamento. Este processo encontra-se em contínua evolução, reinterpretação/re-internalização, ou seja, "o desenvolvimento, neste caso, [...] se dá não em círculo, mas em espiral, passando por um mesmo ponto a cada nova revolução, enquanto avança para um nível superior" (VYGOTSKY, 1991, p. 63). 
Vale ressaltar que enquanto apenas um aluno manifestou não saber o que são transgênicos; $26 \%$ revelaram não saber como se faz um transgênico, embora todos já tenham ouvido falar sobre o assunto e já tenham estudado genética.

"Não entendo nada, só sei que estão fazendo testes para saber qual é e qual não é transgênico". Aqui temos indícios de que aquilo que é veiculado sem a intenção explícita de explicar o que é um transgênico tem se sobressaído aos conhecimentos trabalhados na escola. É possível inferir, ainda, que o fato de um assunto estar na pauta de discussões cotidianas, motivadas por preocupações de cunho político, econômico, social, ecológico, não garante aos sujeitos o entendimento sobre ele.

Na resposta à questão "você conhece algum transgênico", todos os alunos citaram alguns dos exemplos constantemente veiculados pelos meios de comunicação de massa e, portanto, os mais produzidos comercialmente, destacando-se a soja, o milho, o tomate e a batata. Em um número menor de respostas foram considerados a banana, arroz, algodão, canola, feijão, trigo e ervilha. Entre os animais, somente em uma resposta foi mencionado o frango. Nenhum aluno destacou o avanço inicial dessa biotecnologia na transformação de microorganismos, como bactérias, que logo passaram a ser utilizados para a produção comercial do hormônio do crescimento e da insulina e, posteriormente, no processamento de outros medicamentos e alimentos. Um número pequeno de alunos considerou que "existem remédios transgênicos". Outros alunos incluíram "cereais matinais", "bebidas", "refrigerantes", "macarrão instantâneo" e "bolacha" na lista de transgênicos.

Este resultado pode ser explicado pela intensa divulgação, por parte de organizações de oposição à técnica de transgenia, dos possíveis produtos que em sua composição podem ter algum componente oriundo de um organismo transgênico. Apesar de conhecerem a palavra, não conhecem o conceito.

Quando questionados se tinham utilizado algum produto oriundo de transgênicos, $44 \%$ dos alunos revelaram não saber; 34\% descreveram que já haviam consumido, sendo citados os derivados da soja e do milho, a batata, o macarrão instantâneo, os cereais matinais e produtos importados; $20 \%$ responderam que não utilizavam. Alguns estudantes teceram críticas ao fato de as embalagens não trazerem em seus rótulos informações com as quais possam saber o que estão consumindo: "Não há como saber, pois muitos dos produtos transgênicos passam despercebidos pelas autoridades e são vendidos como produtos que não sofreram nenbum tipo de modificacõoes".

A influência exercida pela mídia no posicionamento das pessoas sobre os transgênicos por meio da divulgação de debates polêmicos gerados entre a comunidade científica, o poder econômico, jurídico e público, em geral, principalmente neste momento em que se elaboram modelos para a regulamentação dos transgênicos, pode ser observada nas opiniões dos alunos sobre as vantagens e desvantagens dessa biotecnologia.

Em relação às vantagens, foram destacadas por ordem decrescente de incidências: a resistência a herbicidas, pragas e patógenos, resultando na redução do uso de agrotóxicos; o aumento da produtividade e do valor nutricional dos alimentos; prolongamento do estágio de amadurecimento dos frutos; redução dos custos para o agricultor; redução da fome, entre outras. Algumas respostas ilustram o que estamos dizendo: "As plantas ficam mais resistentes diminuindo os prejuízos"; "O organismo pode combater uma doença parasitária, ter mais vitaminas, aumentar sua produção etc.". 
Provavelmente referindo-se à aplicação desses organismos como biorreatores, um aluno considerou que os transgênicos "podem curar doenças". Outro manifestou-se com as seguintes palavras: "A vantagem é que os transgênicos não causam muitas doenças, porque não é utiliz̧ado agrotóxico".

Oito alunos não responderam ou revelaram, por exemplo, que "não saberia dizer por falta de conhecimento".

Em suas opiniões acerca das desvantagens dos transgênicos, 83\% dos alunos entrevistados conceberam que são prejudiciais à saúde humana, podendo causar alergias, toxidez, várias doenças, inclusive genéticas, e até mesmo morte, opondo-se ao posicionamento do aluno que considerou que os transgênicos "curam doenças": "As causas que podem tražerpara nossas vidas são: alergias, podem ser tóxicos. Camundongos que se alimentaram de batatas transgênicas morreram"; "Podem causar ou desenvolver alguma doença e até mesmo matar".

Um dos principais focos dos debates e questionamentos sobre os transgênicos refere-se à saúde humana. As controvérsias em relação aos riscos dos alimentos transgênicos são bastante acirradas mesmo entre a comunidade científica. Os cientistas que defendem a biotecnologia argumentam que a possibilidade de os transgênicos causarem distúrbios como hipersensibilidades alérgicas e toxidez não é maior da que existe pelo consumo de alimentos desenvolvidos pelo melhoramento convencional. Sobre esta questão, Nodari e Guerra (2003, p. 108) ressaltam:

Como o transgene confere novas características, em geral pouco avaliadas quanto aos seus impactos, ainda não foi gerada uma base de conhecimento para abordar corretamente este assunto. Neste sentido, as liberações para o cultivo comercial de plantas transgênicas devem ser precedidas por estudos nutricionais e toxicológicos de longa duração.

A Organização Mundial da Saúde (OMS) desenvolveu testes bastante rigorosos e padrões internacionais para detectar substâncias com potencial alergênico. Antes de serem liberados ao mercado, os OGMs são submetidos a eles. A comercialização da soja modificada pela transferência do gene que codifica para o aminoácido metionina na castanha-do-pará, por exemplo, foi suspensa em função de o produto ocasionar reações alérgicas em algumas pessoas.

Além dos riscos de alergias e toxicidade, alguns críticos argumentam que alimentos transgênicos, que contêm genes de resistência a antibióticos, podem disseminar a resistência para bactérias.

Outra controvérsia observada nas respostas dos alunos sobre vantagens e desvantagens dos transgênicos refere-se ao valor nutricional. Diferentemente das respostas que consideraram que alimentos oriundos de organismos transgênicos são mais nutritivos, dois alunos descreveram, como desvantagem, o fato de estes alimentos serem menos nutritivos.

Em relação à equivalência nutricional, pesquisas realizadas com soja transgênica e não transgênica não revelaram diferenças entre os constituintes nutricionais dessas duas categorias de alimentos (ZANCAN, 1999). 
Ainda sobre as vantagens e desvantagens dos transgênicos, muitos alunos destacaram também, em suas respostas, que os transgênicos podem representar riscos de desequilíbrio ou impacto ambiental.

Em relação ao meio ambiente, os debates mais polêmicos se referem à ameaça à biodiversidade devido ao fluxo gênico ou transferência dos transgenes de uma população para outra, trazendo, como conseqüência, deslocamento ou eliminação de espécies silvestres, exposição de espécies a novos patógenos, criação de plantas daninhas de difícil controle, poluição e erosão genética (NODARI e GUERRA, 2003). No entanto, segundo Cançado (2000), o risco de fluxos de genes engenheirados para espécies silvestres seria mais crítico em regiões onde se localizam os similares silvestres, o que poderia ocorrer nos centros de origem. Para que isso acontecesse, seria necessário que o organismo transformado fosse mais adaptado ao ambiente em que foi introduzido do que as espécies silvestres com as quais ele compete. Klinger, Elan e Ellstrand (1991) ressaltam que o fluxo gênico entre diferentes espécies é extremamente complexo e, para que ocorra, é necessário quebrar várias barreiras de isolamento reprodutivo.

Outra preocupação, levantada principalmente por ambientalistas, refere-se à ação de genes inseticidas inseridos em lavouras geneticamente modificadas, os quais poderiam eliminar insetos importantes para a polinização e para a cadeia alimentar.

Embora no meio científico ocorram discussões dessa natureza - mesmo que apresentem explicações e fundamentações divergentes - o que chega aos alunos são informações aligeiradas, "comandos" insuficientes para garantir que defendam posicionamentos pautando-se em conhecimentos sistematizados.

Seus posicionamentos não se restringiram somente à saúde e ao meio ambiente, mas também às implicações sócio-econômicas resultantes do cultivo dos transgênicos: "Prejudica os produtores que não plantam transgênicos"; "As multinacionais terão domínio sobre os produtores, porque as sementes não são férteis".

Sobre as reações adversas do público perante esta nova era biotecnológica, Leite (2000, p. 40) considera que:

A repulsa aos alimentos transgênicos parece ser apenas o topo visível de uma profunda desconfiança, alimentada pela percepção de que a fronteira entre natureza e cultura - que, diga-se, sempre foi móvel e historicamente determinada - está sendo retraçada não tanto sob os ditames de uma ciência pura e desinteressada, mas sim, predominantemente, sob interesses daquilo que se poderia denominar "complexo industrial-biotecnológico.

Enquanto estas questões vão se tornando cada vez mais polêmicas, a produção e o consumo de derivados de transgênicos já são realidade em muitos países. No Brasil, embora haja, ainda, grande resistência para a liberação e comercialização desses produtos, safras da soja transgênica Roundup Ready foram liberadas para serem comercializadas até 2005. Também não é desconhecido da população e autoridades que plantios "clandestinos" ocorrem há muitos anos em alguns estados. 
Os estudantes destacaram, ainda, como desvantagem "a falta de informação e de resultados concretos das consequiências que os transgênicos podem causar". Alguns revelaram não ver nenhuma desvantagem nesta biotecnologia e outros não responderam ou declararam não saber.

Finalmente, quando os estudantes foram solicitados a dizer se eram contra ou a favor aos transgênicos, obtivemos os seguintes dados: $40 \%$ posicionaram-se contrários, $34 \%$ mostraram-se favoráveis e $26 \%$ disseram não ter opinião formada, destacando-se frases como: "Contra, porque não sei que benefícios eles trazem"; "A favor, porque não foi comprovado ainda que eles causam reaçoes que possam prejudicar o homem"; "Ainda não tenho uma opinião formada sobre este assunto".

\section{Considerações finais}

As concepções e opiniões manifestadas pelos estudantes do Ensino Médio em relação aos transgênicos revelaram que tais alunos ainda não possuem uma compreensão que ultrapasse as discussões de senso comum.

Apesar de empregar termos amplamente divulgados pela mídia e em situações de ensino, a maioria demonstrou dificuldades em esclarecê-los, reduzindo o conceito à palavra ou à definição destituída de significado. Tais dificuldades podem estar relacionadas à falta de domínio da base científica que possibilitou os atuais avanços biotecnológicos, decorrente de um ensino que valoriza apenas a memorização.

Sobre esta questão Vygotsky diz:

[...] a experiência pedagógica nos ensina que o ensino direto de conceitos sempre se mostra impossível e pedagogicamente estéril. O professor que envereda por esse caminho costuma não conseguir senão uma assimilação vazia de palavras, um verbalismo puro e simples que estimula e imita a existência dos respectivos conceitos na criança mas, na prática, esconde o vazio. Em tais casos, a criança não assimila o conceito, mas a palavra, capta mais de memória que de pensamento e sente-se impotente diante de qualquer tentativa de emprego consciente do conhecimento assimilado. No fundo, esse método de ensino de conceitos é a falha principal do rejeitado método puramente escolástico de ensino, que substitui a apreensão do conhecimento vivo pela apreensão de esquemas verbais mortos e vazios. (VIGOTSKI, 2001, p. 247)

Verificou-se, também, que as opiniões dos estudantes sobre aplicações e implicações dos transgênicos expressam idéias muitas vezes equivocadas e sensacionalistas divulgadas pela mídia.

Cabe, portanto, à escola promover uma educação que possibilite aos estudantes a apropriação de conhecimentos com base nos quais possam tomar decisões conscientes e esclarecidas. Os dados analisados indicam que, no que se refere aos transgênicos, os conhecimentos ensinados na escola não têm possibilitado aos sujeitos o entendimento da realidade atual e, por conseguinte o pensar, falar e agir cientificamente. 
Saber científico e conhecimento espontâneo...

Quanto a este aspecto, concluímos citando Palangana, Galuch e Sforni (2002, p. 121), que ressaltam que "a aprendizagem vai além da apropriação de um conteúdo específico e significa, também, o desenvolvimento de capacidades cognitivas que possibilitem a ação sobre o conhecimento re-elaborado".

\section{Referências}

AMORIM, A. C. R. O ensino de Biologia e as relações entre Ciência/Tecnologia/ Sociedade: O que dizem os professores e o currículo do Ensino Médio? In: ENCONTRO "PERSPECTIVA DO ENSINO DE BIOLOGIA", 6., 1997, São Paulo. Anais... São Paulo: Faculdade de Educação da USP, 1997. p. 74-77.

ANDRIOLI, A. I. O retorno do Terminador. Revista Espaço Acadêmico, n. 58, março de 2006. Disponível em: <http://www.espacoacademico.com.br/058/58andrioli.htm>. Acesso em: 15 out. 2007.

BACHELARD, G. A formação do espírito científico. Rio de Janeiro: Contraponto, 1996.

BANET, E.; AYUSO, E. Introducción a la genética en la enseñanza secundaria y bachillerato: I contenidos de enseñanza y conocimientos de los alumnos. Investigación y experiencias didácticas. Enseñanza de las Ciencias, Barcelona, v. 13, n. 2, p. 137-153, 1995.

BASTOS, F. Construtivismo e ensino de ciências. In: NARDI, R. (Org.). Questões atuais no ensino de ciências. São Paulo: Escrituras, 1998. p. 9-25.

BIZZO, N.; KAWASAKI, C. S. Este artigo não contem colesterol: pelo fim das impostoras intelectuais no ensino de ciências. Projeto-Revista de Educação, Porto Alegre, v. 1, n. 1, p. 25-34, 1999.

BUGALLO, A. R. La didáctica de la genética: revisión bibliográfica. Enseñanza de las Ciencias, Barcelona, v. 13, n. 3, p. 379-385, 1995.

CABALLER, M. J.; GIMÉNEZ, I. Las ideas del alumnado sobre el concepto de célula al finalizar la educación general básica. Enseñanza de las Ciencias, Barcelona, v. 11, n. 1, p. 63-68, 1993.

CANÇADO, G. M. A. Plantas transgênicas e biossegurança. Informe Agropecuário, Belo Horizonte, v. 21, n. 204, p. 14-19, 2000.

FARAH, S. B. DNA, segredos e mistérios. São Paulo: Sarvier, 1997.

GIORDAN, A.; VECCHI, G. As origens do saber: das concepções dos aprendentes aos conceitos científicos. 2. ed. Porto Alegre: Artes Médicas, 1996.

KLINGER, T.; ELAN, D. R.; ELLSTRAND, N. C. Radish as a model system for the study of engineering gene escape rates via crop-weed matting. Conservation Biology, Boston, Massachussets, v. 5, n. 4, p. 531-535, 1991. 
Pedrancini, V. D. et al.

KREUZER, H.; MASSEY, A. Recombinant DNA and biotechnology: a guide for teachers. 2. ed. Washington: ASM Press, 2001.

LEITE, M. Biotecnologias, clones e quimeras sob controle social: missão urgente para a divulgação científica. São Paulo em Perspectiva, São Paulo, v. 14, n. 3, p. 40-46, 2000.

NATADZE, R. G. A aprendizagem dos conceitos científicos na escola. In: VYGOTSKY, L. S; LEONTIEV, A.; LURIA (Orgs.). Psicologia e Pedagogia II. Lisboa: Estampa, 1991. p. 27-34.

NODARI, R. O.; GUERRA, M. P. Plantas transgênicas e seus produtos: impactos, riscos e segurança alimentar (Biossegurança de plantas transgênicas). Revista de Nutrição, Campinas, v. 16, n. 1, p. 105-116, 2003.

PALANGANA, I.; GALUCH, M. T. B.; SFORNI, M. S. F. Acerca da relação entre ensino, aprendizagem e desenvolvimento. Revista Portuguesa de Educação, Braga, Portugal, v. 15, n. 1, p. 111-128, 2002.

PEDRANCINI, V. D. et al. Ensino e aprendizagem de Biologia no Ensino Médio e a apropriação do saber científico e biotecnológico. Revista Electrónica de Enseñanza de las Ciencias, v. 6, n. 2, p. 299-309, 2007. Disponível em: <http://www.saum.uvigo.es/ reec/>. Acesso em: 20 jul. 2007.

QUECINE, V. M.; VIEIRA, M. L. C. Plantas transgênicas. In: SERAFINI, L. A.; BARROS, N. M.; AZEVEDO, J. L. (Coords.). Biotecnologia na agricultura e na agroindústria. Guaíba: Agropecuária, 2001. p. 279-331.

SUZUKI, D. T. et al. Introdução à genética. 4. ed. Rio de Janeiro: Guanabara Roogan, 1989.

TORRES, A. C.; CALDAS, L. S.; BUSO, J. A. Cultura de tecidos e formação genética de plantas. 2. ed. Brasilia: Centro Brasileiro Argentino de Biotecnologia, 1999.

VIGOTSKI, L. S. A construção do pensamento e da linguagem. São Paulo: Martins Fontes, 2001.

$$
1991 .
$$

A construção do pensamento e da linguagem. São Paulo: Martins Fontes,

ZANCAN, G. T. Alimentos transgênicos: riscos à saúde. Disponível em: <http:// www.portalrural.com.br/agroartigos/print.html?=artigo38.html>. Acesso em: 21 jul. 1999.

Artigo recebido em abril de 2007 e aprovado em outubro de 2007. 